Revista de Derecho YACHAQ N. ${ }^{\circ} 12$

Centro de Investigación de los Estudiantes de Derecho (CIED)

Universidad Nacional de San Antonio Abad del Cusco

ISSN: 2707-1197 (en linea)

ISSN: 1817-597X (impresa)

Fecha de recepción: 24/10/2020

Fecha de aceptación: 08/01/2021

[pp. 197-202]

\title{
La crisis peruana: perspectiva constitucional
}

\author{
Rafael Sierra Casanova ${ }^{[*]}$
}

\section{- ¿Qué es la teoría de los pesos y contrape- sos? ¿Cómo se refleja o aplica en el Perú? Respecto a la reciente inestabilidad fun- cional entre el poder legislativo y el poder ejecutivo en el Estado peruano ¿Cómo se ha visto afectado esta teoría?}

Nosotros tenemos que recordar que nuestra constitución tiene clásicamente definida una parte orgánica y una parte dogmática, la parte orgánica de inicio se entiende que tiene por objeto regular la forma como interaccionan los distintos poderes del estado, aunque en puridad se debe entender que el poder es en realidad uno solo y lo que hace la constitución es poder diseñar un mecanismo que permite identificar como se distribuye este poder a través de los distintos poderes constituidos regulados en ella dentro de los denominados clásicos poderes del estado y los órganos constitucionales autónomos, en este contexto la teoría de pesos y contrapesos tiene por objeto precisamente equilibrar estas relaciones en el ejercicio del poder que tienen las distintas instituciones del estado de tal suerte que todas ellas funcionan como un engranaje, en la cual las distintas instituciones que conforman nuestro estado busquen controlarse entre sí, lo cual va a restar la posibilidad de escenario de ejercicio abusivo del poder por alguno de ellos, reducir la posibilidad de ingresar en escenarios de dictaduras bajo revestimientos aparentemente constitucionales y mantener una estabilidad en nuestro estado. En el Perú básicamente eso se refleja en el hecho de que el ejecutivo, por ejemplo, tiene potestades de poder controlar o cuestionar algunas actuaciones

[*] Abogado por la UNSAAC, egresado de la Maestría en Derecho Civil y Procesal Civil de la UNSAAC, estudios de maestría en Derecho Constitucional y Procesal Constitucional en la misma universidad. Ex docente universitario. Juez Especializado Civil Provisional. Realizó estudios de "Justice from a Gender Perspective" en International Law Enforcement Academy - San Salvador. Autor de diversos artículos en revistas de publicación de especialidad y coautor del Código Procesal Constitucional Comentado de Gaceta Jurídica. 
propias del legislativo ya sea mediante la posibilidad de observar algunas leyes para que los proyectos de ley o leyes ya sancionadas sean repensadas por el congreso e incluso la posibilidad de cuestionarlas mediante un proceso de inconstitucionalidad donde va a ser otro ente autónomo el que finalmente determine si una ley es constitucional o no. Lo propio ocurre, por ejemplo, en el caso que el poder judicial frente a una ley dictada por el congreso puede de forma excepcional inaplicar la misma mediante el control difuso si juzga que esta norma es inconstitucional y por tanto el legislativo habría excedido en el ejercicio de sus facultades al dictar la misma en un caso en concreto, y lo propio va a ocurrir con los sistemas que están diseñados como procesos ante el congreso, como por ejemplo va a ser la posibilidad de censurar a algún ministro, de otorgar el voto de confianza o no cuando se plantea un cuestión de confianza. Lo cual permite equilibrar la relación que existe entre los poderes del estado y mantener estabilidad y seguridad jurídica en nuestro país, definitivamente cuando alguna de estas facultades de estabilización que tienen algunos poderes del estado respecto a otros se ejerce de forma irrazonable e injustificada, entramos a un escenario en el cual se puede generar inestabilidad y precisamente cuando nosotros nos preguntamos y tratamos de dar respuesta a la última parte de la pregunta que se vincula a como se habría visto afectada esta teoría, yo creo que en puridad, como tal, la teoría no se ha visto afectada porque hemos podido advertir que se han utilizado procedimientos constitucionales para poder mantener el equilibrio de poder que ha existido, sin embargo, lo que creo que ha faltado y adelanto un poco el tema en análisis es que el Tribunal Constitucional que era el órgano encargado de poder delimitar los lineamiento para marcar las pautas que permitan establecer si hubo algún exceso o no en alguna de las facultades ejercidas ya sea por el ejecutivo o legislativo en la última crisis que hemos tenido, omitió o decidió no pronunciarse sobre el tema y que considero que es el principal resquicio que ha habido en la última crisis que hemos enfrentado.

\section{- ¿Por qué se presentó una demanda com- petencial frente a la vacancia?}

En puridad no se presentó la demanda competencial frente a la vacancia propiamente dicha, porque aun Martin Vizcarra no había sido vacado, sino se presentó la demanda competencial frente al inicio del procedimiento de vacancia dado que lo que se cuestionaba era que la forma como había procedido el congreso implicaba un ejercicio abusivo e inconstitucional de las facultades que tenían, y esto por qué, porque si es que acaso la demanda fuera por el hecho de utilizar la facultad de poder vacar a un presidente pues llanamente la demanda habría sido declarada improcedente, sino el tema era cómo o por qué razones se empezó a implementar el procedimiento de vacancia del ex presidente Vizcarra, y esa es la razón fundamental, yo creo que el punto central era cuestionar si existía una razón suficiente para poder invocar la causal de incapacidad moral permanente que regula nuestra constitución para este tipo de procesos políticos como es la vacancia.

\section{- De acuerdo al último pronunciamiento del Tribunal Constitucional, ¿Se ha vul- nerado el debido proceso que sigue una demanda competencial? ¿Qué más se esperaba por parte del Tribunal Consti- tucional?}

Bueno el Tribunal constitucional en un pronunciamiento mayoritario ha decidido declarar la sustracción de la materia, en cuya virtud en puridad no se ha pronunciado respecto a si existía o no existía un debido proceso en el procedimiento de vacancia seguida contra Martin Vizcarra, ahora qué se esperaba por parte del Tribunal Constitucional, yo creo que una de las labores más importantes que tiene el Tribunal Constitucional conforme lo establece la constitución y su propia ley orgánica es 
que se constituye en el máximo intérprete de la constitución, en este contexto si bien es cierto el Tribunal Constitucional no podía abocarse a poder determinar qué cosas bajo un supuesto de numerus clausus, por así decirlo, o un supuesto específico de casos concretos, qué podía ser considera un caso de incapacidad moral permanente, sí puedo establecer pautas que permitan poder determinar cuándo es que constitucionalmente se puede considerar valido un procedimiento de vacancia por invocación de la incapacidad moral permanente y esto básicamente porque existen mucho temas en los cuales si es que nosotros dejamos un marco excesivamente abierto de esta norma podríamos incorporar supuestos que generen inestabilidad, por ejemplo, si nosotros en estas próximas elecciones votamos y elegimos un presidente que fuese ateo y él considerase en sus pronunciamiento afirmaciones o publicaciones la profesión de su fe y que en su virtud, por ejemplo, no existe dios, y eso se juzga por un grupo de persona como algo que justifica una incapacidad moral y que al ser pronunciamientos reiterativos terminando siendo una actitud de incapacidad moral permanente, podríamos ver que por ejemplo lesionaría el ejercicio de un derecho fundamental de este hipotético presidente de la república como es la libertad de credo, entonces uno de los parámetros que por ejemplo pudo definir el Tribunal Constitucional para poder enmarcar cuando nos encontramos frente a un caso de incapacidad moral permanente, es que no va a poder ser encuadrada en dicha figura jurídica un supuesto en el cual el presidente de la republica este ejerciendo legítimamente un derecho fundamental suyo y con eso empezar a tratar de darle contenido a esta norma constitucional, era la labor del Tribunal Constitucional y en dicho trabajo poder pronunciarse respecto a la constitucionalidad o no del caso concreto. Yo creo que, en realidad, desde la perspectiva de la población y también del mundo académico, se esperaba mucho más del pronunciamiento del Tribunal Constitucional.
- ¿Qué presupuestos abarca la sustracción de la materia?, según el expediente 00002-2020-PC/TC ¿Hubo sustracción de la materia?

La sustracción de la materia en puridad es una institución que proviene del derecho procesal que se vincula a la falta de un presupuesto material de la pretensión como es el interés para obrar, el interés para obrar se entiende como el estado de necesidad producto de una prestación insatisfecha o de una incertidumbre jurídica no resuelta, es esta situación de necesidad que tengo yo por la cual acudo al órgano jurisdiccional para que me solucione el conflicto, ordene que alguna persona que me deba algo satisfaga la prestación a mi favor o en el caso de incertidumbre jurídica estas sean esclarecidas. En materia constitucional vamos a ver que de forma genérica podemos encontrar supuestos de sustracción de la materia cuando existe una irreparabilidad del derecho o cuando a desaparecido aquel acto que amenazaba con vulnerar este derecho pero incluso conforme al artículo 1 de Código Procesal Constitucional, aun cuando el derecho sea irreparable si es que acaso el nivel de la transgresión de la Constitución o de un valor constitucional ha sido altamente lesivo, el Tribunal Constitucional y los jueces constitucionales deben emitir un pronunciamiento no con el objetivo de restituir el derecho porque se habrá vuelto en irreparable sino con el objetivo de establecer parámetros de interpretación constitucional que con una suerte de obiter dictum o fin vaticinador de los pronunciamientos del TC, persuada a los funcionarios, particulares y el propio Estado de no incurrir en determinado tipo de conductas porque estas de repetirse pueden vulnerar la Constitución. Entonces vemos que incluso la sustracción de la materia a diferencia de lo que ocurre el proceso civil, en el proceso constitucional es diferente e incluso existe la posibilidad de que los magistrados aun cuando se configure la sustracción de la materia emita pronunciamiento de fondo. 
En el presente caso, yo respetuoso de los pronunciamientos de nuestros máximos tribunos considero que en puridad no ha habido una sustracción de la materia en tanto lo que se debía de analizar y cuestionar es que si la forma como se diseñó el procedimiento de vacancia fue constitucionalmente válida y creo que esta incertidumbre jurídica que resulta de la indefinición normativa que existe respecto a los límites constitucionales que debe tener este procedimiento tanto desde una perspectiva procesal como por ej. Las garantías que se deben ofrecer respecto al ejercicio del derecho de defensa, por ej. Identificar claramente el supuesto de hecho específico que justifica que la causal de vacancia y que sea sobre ese hecho específico que se materialice le debate dentro del procedimiento parlamentario y que en ese procedimiento se justifique la decisión parlamentaria como también aspectos de connotación sustantiva como les decía límites respecto a la identificación del contenido material de la causal en sí misma, como por ej. Que esta no puede implicar la posibilidad de considerar como un caso de incapacidad moral permanente el ejercicio de un derecho fundamental entonces en puridad, yo considero que no hubo sustracción de la materia. Más allá de que el tribunal por mayoría así lo declaró y que siguiendo a los pronunciamientos de los votos en minoría había razones para emitir un pronunciamiento de fondo.

\section{- ¿Puede desprenderse desde la Constitu- ción algún vacío en la manera como se ha dado el proceso de vacancia?}

Yo considero que no, y esto en el entendido que nuestra constitución en puridad es una norma que esta básicamente integrada por normas que tienen la estructura de un principio que son normas que no responden a la estructura clásica de supuesto de hecho, nexo, consecuencia jurídica sino constituye como dice Robert Alexis: una suerte de mandatos de optimización para que se vean las cosas en la mayor medida de lo posible dentro de las posi- bilidades fácticas y jurídicas. En este contexto dada la estructura normativa de principios la apertura de estos dispositivos permiten a los intérpretes la posibilidad de vía interpretación completar todo nuestro diseño constitucional como un engranaje bajo parámetros de consistencia y coherencia normativa, en tal virtud yo creo que nuestra norma constitucional no va identificar vacíos dentro del procedimiento de vacancia lo que si faltaría es que vía interpretación se les dé contenidos a los mismo y precisamente el Tribunal Constitucional es el llamado para completar estos aspectos que podrían ser considerados indeterminados más no vacíos en puridad.

\section{$\rightarrow \quad$ ¿Qué tan difícil es actualmente el cambio de Constitución? ¿Es beneficioso o no, si se llegara a concretar?}

Yo creo que si nos preguntamos hace algún tiempo si era difícil vacar a un presidente pues antes de Pedro Pablo Kuczynski, podríamos decir: bueno, si parece difícil vacar un presidente.

Si nos preguntamos ¿Sería posible disolver un congreso? Pues desde la década del 90 hasta el anteaño, podríamos decir, si parece muy difícil disolver un congreso.

Pero si me preguntas ahora ¿Es difícil actualmente el cambio de la Constitución? Pues te respondería pues si parece difícil un cambio de Constitución. Pero lo cierto es que, como ha ocurrido con la vacancia de nuestros últimos presidentes, con la disolución del penúltimo congreso, no es algo que en la práctica sea muy difícil, basta implementar un procedimiento que prevea nuestra propia Constitución para una reforma total de la misma y como hemos visto en el proceso de referéndum, pues hay una alta tendencia de la población a modificar nuestras normas constitucionales. Pero yo creo que una respuesta así, termina siendo una respuesta parcial e insuficiente porque únicamente se refiere a la posibilidad material de poder modificar nuestra constitución, $\mathrm{y}$ es que nosotros tenemos que al momento 
de reflexionar respecto a la posibilidad de lograr un cambio en la Constitución, entender el contexto en el cual nosotros nos encontramos, tenemos a un Estado que entra al bicentenario de su independencia, sin embargo es recién con la Constitución de 1979 que se dio indicios que nuestro sistema jurídico procesal se empezaba a materializar intentos concretos por entender que la Constitución es una norma muy importante de nuestro sistema normativo vigente y que se debe cumplir, sin embargo el Tribunal de Garantías Constitucionales, como lo establecen los historiadores y estudiosos del derecho, no dio la talla para proteger a la Constitución o no dio la talla para realizar las funciones que esta le encomendaban. Incluso con la Constitución de 1993, durante la década del 90, la actividad del Tribunal Constitucional ha sido bastante exigua, entonces, es a partir del año 2000 en adelante que recién en nuestro sistema jurisprudencial empezamos a desarrollar un poco este concepto de respeto a nuestra Constitución, de ir dándole contenido a nuestras normas constitucionales, ir desarrollando nuestra Constitución logrando que esta Constitución de 1993, más allá de las condiciones de origen cuestionable, que se puedan objetar, es una Constitución que se ha ido dinamizando y adaptando a nuestra realidad y logrando una suerte de tutela de derechos fundamentales, un poco más dinámica y actual, logrando incluso en sede jurisdiccional modificaciones que no se lograban en sede legislativa, como por ejemplo el tema de la protección de las familias ensambladas, el tema de la protección de los derechos de los concubinos, entonces con todo esto, lo que quiero decir es que nuestro entendimiento respecto a ¿Que es una Constitución? ¿Cuál es la importancia de la Constitución y el respeto que le debemos a nuestra Constitución y los efectos que nuestra Constitución tiene en nuestro país? Es un desarrollo reciente porque nosotros en 200 años de historia, recién tenemos 20 años de jurisprudencia que intensan sobre el tema. Es cierto que antes podemos encontrar alguna que otro pronunciamiento relevante, pero es muy escaso, en este contexto yo creo que un cambio de Constitución en esta situación de desarrollo jurisprudencial, desarrollo del propio derecho constitucional no es lo más adecuado, ni es lo más beneficioso. Lo que yo creo es que nosotros debemos de ajustar la Constitución en algunos aspectos, realizar algunas reformas constitucionales en algunos puntos que creo que se puede ajustar nuestra Constitución, pero no refundar el Estado en su integridad porque precisamente el desarrollo de la institucionalización y el desarrollo de las pautas constitucionales no es un proceso que solo se materializa con el hecho de dar un texto normativo sino en realidad que es un resultado de la interpretación de este texto normativo. Entonces yo creo que nuestra Constitución tampoco ya requiere en sumo ser reformado en su totalidad porque muchos extremos de la misma incluso están sujetos a la Convención Americana de Derechos Humanos, entonces van a ver algunos aspectos de nuestra propia Constitución que se llaman las cláusulas pétreas de la Constitución o la fórmula basilar de la Constitución que sería en la práctica inviable de modificar, ni siquiera dando una nueva Constitución, entonces yo creo que es innecesario someter al Estado peruano a un procedimiento de incerteza de un año que dure una asamblea constituyente para dictar una nueva Constitución, sin perjuicio de poder hacer las reformas Constitucionales que correspondan, los ajustes que correspondan o los distintos mecanismos que prevé nuestra Constitución para tal efecto.

\section{CONCLUSIÓN}

Sin duda yo creo que los últimos años han demostrado que nuestra constitución en realidad es una norma que aun cuando pudiese tener algunos ajustes nos permite lograr cierta estabilidad jurídica, vamos a ver que como resultado de las diferentes crisis de poder que ha habido en nuestro país en los últimos 20 años no hemos tenido gobiernos manifiestamente al menos dictatoriales hemos podido controlar 
actos de las distintas entidades del estado, poder atacar incluso a las máximas autoridades del Poder Ejecutivo del Congreso, del Poder Judicial, por tanto yo considero nuestra constitución en realidad sí funciona, el Tribunal Constitucional ha reconocido muchos Derechos a muchas personas que antes no estaban estipulados y que incluso hasta la fecha no están estipulados claramente en nuestro sistema legal vigente, han resuelto temas de alta relevancia dotando no solo de certeza jurídica a nuestra sociedad sino solucionando temas tan sensibles como el tema de la prescripción de los cobros de impuestos a importantes grupos empresariales en este contexto yo creo que el problema no es el diseño constitucional, no es en puridad nuestra constitución, sino que en muchos sectores de nuestra población no utilizan la constitución para la solución de sus conflictos, la solución ya sea de la tutela de derechos concretos, o también la solución respecto a problemas constitucionales de control norma- tivo o incluso temas de procesos competenciales como en el caso que amerita esta entrevista, entonces yo creo que más bien debemos dejar que nuestra Constitución con los ajustes que podamos hacer se desarrolle mucho más, se dinamice mucho más y confiemos en nuestros tribunales para que vía interpretación los dispositivos constitucionales se conviertan y trasunten en las normas que van a permitir un real respeto de los derechos fundamentales y un equilibrio de poder en el estado, este trabajo no se logra convocando una asamblea constituyente, sesenta sabios que nos digan cual es la fórmula mágica para lograr un estado perfecto, sino es todo un proceso evolutivo dado por el desarrollo propio de la sociedad y por sus tribunos por los jueces que se encargan precisamente de darle contenido material a estas normas que sin duda no están exentos de poder cometer un error pero creo que se constituyen en el camino correcto para poder optimizar el contenido constitucional. 